\title{
NOTÍCIAS SOBRE ALGUNS ESTUDOS GEOGRÁFICOS QUE ANTECEDERAM A CRIAÇÃO DE BRASÍLIA ${ }^{1}$
}

Dora de Amarante Romariz ${ }^{2}$

Curiosamente, pois tantos anos já são passados, apareceram, tanto no Brasil quanto no estrangeiro, referências a estudos e trabalhos de campo que foram feitos (em 1947) visando à escolha do sítio para a localização do "então" futuro Distrito Federal.

Tomando conhecimento das mesmas, e por ter participado desses trabalhos, verifiquei que alguns fatos mencionados nessas publicações apresentavam várias distorções.

Sendo eu, praticamente, um dos últimos "remanescentes" capazes de relatar o que realmente ocorreu, aceitei, quando convidada, elaborar a presente comunicação, a fim de que a veracidade da História seja preservada.

Para a presente comunicação utilizei-me, além de lembranças e anotações pessoais, extraídas de meus cadernos de campo, de toda a documentação oficial contida em artigos publicados na época.

A ideia de mudança da capital do país já era muito antiga, desde que Salvador era capital (de 1578 a 1763) já se falava nas vantagens de se mudar a capital para o interior. Em 1763 a capital foi transferida mas... para o Rio de Janeiro, continuando, portanto, no litoral.

Só em 1891, com a $1^{\text {a }}$ Constituição Republicana é que foi reservada uma área no Planalto Central para esse fim, área essa já preconizada por VARNHAGEM (Visconde de Porto Seguro) que passou a ser enquadrada pelo Retângulo Cruls. Esta designação derivou do fato de ter sido a área estudada pela Missão Cruls, em 1829.

Bem mais tarde, em 1922, o presidente Epitácio Pessoa assinou um decreto determinando a efetivação da mudança do sítio Cruls, mas condicionou a mudança a uma oportunidade não definida.

\footnotetext{
${ }^{1}$ Palestra realizada no Departamento de Geografia da UNB (dia 12/03/2004).

${ }^{2}$ Geógrafa aposentada do Conselho Nacional de Geografia (IBGE). Bacharel e Licenciada em Geografia e História pela Faculdade Nacional de Filosofia da antiga Universidade do Brasil e Pós-graduada pela FFCL da USP (Departamento de Geografia). Tem especialização em Biogeografia. Foi Professora-visitante da Universidade de Brasília, tendo ministrado no Departamento de Geografia (1º semestre de 1978) no curso de Geografia Biológica. Tem vários trabalhos publicados no Brasil e no exterior.

N.E. Texto autorizado a publicar, pela autora, em 27/03/2017.
} 
As constituições de 1934 e 1937 também “recomendavam" e, assim, o tempo foi passando.

Somente a Constituição de 1946 (no Art. 4º do Ato das Disposições Transitórias) é que determinou: "a Capital da União será transferida para o Planalto Central o Brasil" e estabeleceu o processamento a transferência.

Acontece, porém, que a Constituição só falava em "Planalto Central" e, tendo em vista a sua vastidão, a principal questão passou a ser a de determinar a área mais adequada dentro dessa enorme extensão do território.

O Presidente da República (Eurico Dutra) nomeou, então, uma comissão, composta por 12 técnicos pertencentes a diferentes setores e instituições, dentre os quais se encontravam o Gal. Djalma Poli Coelho, Presidente do IBGE e o Eng. Christovam Leite de Castro, Secretário Geral do Conselho Nacional de Geografia, tendo sido a referida comissão empossada a 19 de novembro de 1946. O Gal. Poli Coelho foi designado para exercer as funções de Presidente dessa Comissão e o Eng. Christovam Leite de Castro as de Diretor da Secção Especializada de Estudos Geográficos da Comissão de Estudos para a Localização da Nova Capital do Brasil.

Iniciando imediatamente seus trabalhos, após sucessivas reuniões técnicas e os indispensáveis estudos de gabinete, foram estabelecidas oito áreas que deveriam ser analisadas durante as pesquisas de campo, fase seguinte dos trabalhos da Secção Especializada de Estudos Geográficos.

As oito áreas escolhidas, quatro em Minas Gerais e quatro em Goiás, foram as seguintes (Mapa 1):

Zona A - Uberaba-Araxá

Zona B - Ituiutaba

Zona C - Uberlândia-Tapaciguara

Zona D - Alto Paranaíba (ou zona de Patos de Minas)

Zona E - Ipameri-Pires do Rio

Zona F - Goiânia-Anápolis

Zona G - Retângulo de Cruls (ou Zona de Planaltina)

Zona $\mathrm{H}$ - Chapada dos Veadeiros

Por ordem do Diretor da Comissão, Eng. Leite de Castro os trabalhos de campo goram divididos em duas expedições: 
1) à primeira foram atribuídos os estudos de detalhe das oito zonas acima referidas, cabendo-lhe realizar levantamentos topográficos e fazer estudos geográficos específicos dos sítios adequados à finalidade visada, quando encontrados.

2) coube à segunda realizar o estudo do Planalto em seu conjunto, para uma compreensão das características gerais dessa região, tendo em vista, principalmente, o estudo e o problema da posição da Nova Capital do País.

Mapa 01:MAPA DO SUDESTE DO PLANALTO CENTRAL DO BRASIL

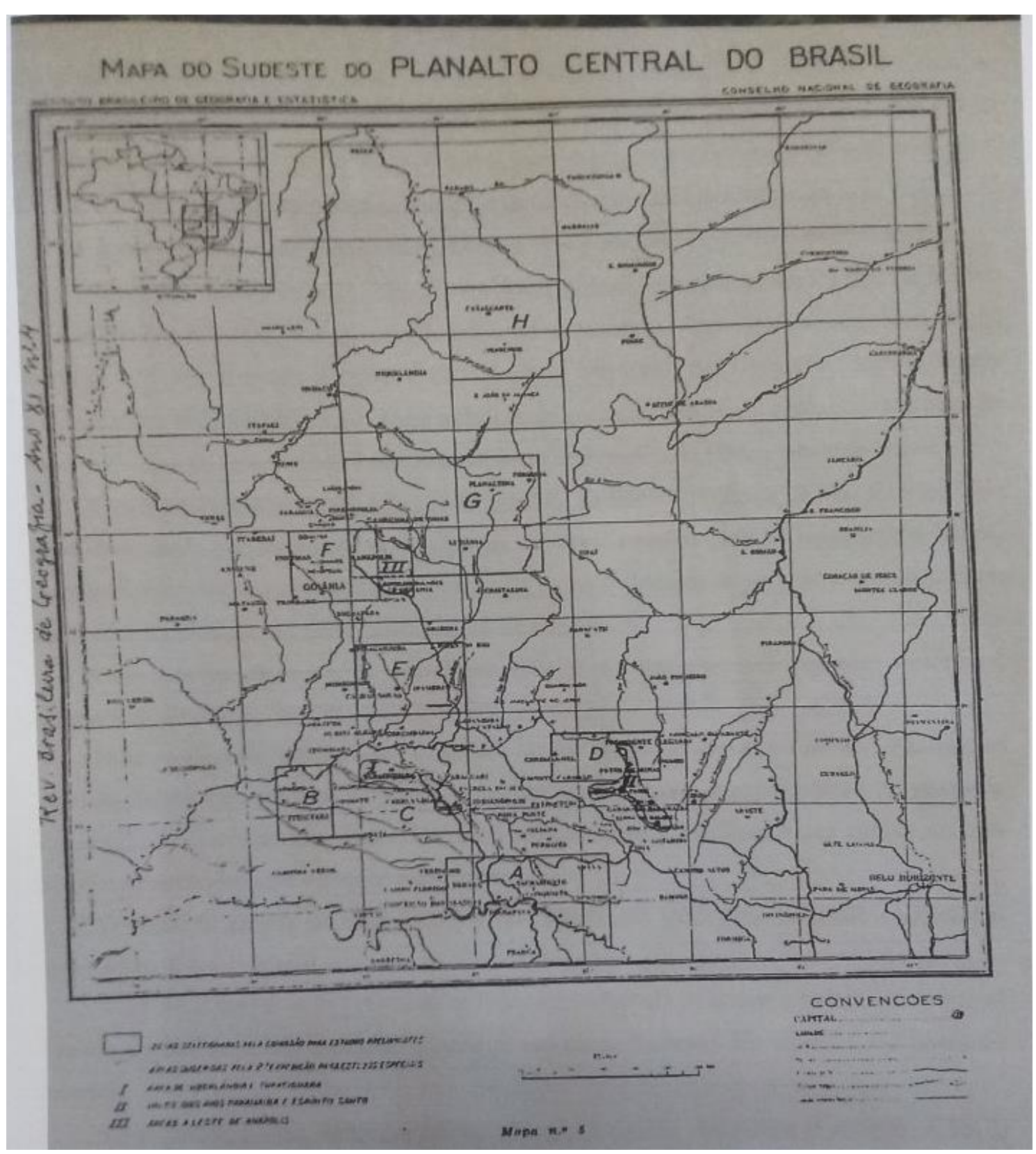


Para chefiar a $1^{\mathrm{a}}$ expedição foi designado o Prof. FRANCIS RUELLAN, Professor do Curso de Aperfeiçoamento de Geógrafos do Conselho Nacional de Geografia. A chefia da $2^{\text {a }}$ coube ao Eng. FÁBIO DE MACEDO SOARES GUIMARÃES, coordenador da Divisão de Geografia do Conselho Nacional de Geografia. Contou, ainda, este grupo, com a orientação científica do Prof. LEO WAIBEL, assistente técnico contratado do Conselho Nacional de Geografia.

Vejamos, rapidamente, como cada um desses dois grupos desenvolveu seus trabalhos.

O primeiro, sob a chefia do Prof. Francis Ruellan, tendo em vista as tarefas que lhe haviam sido atribuídas, necessariamente, teria de ser o mais numeroso. Contou, pois, com cerca de 40 técnicos em sua maioria geógrafos do Conselho Nacional de Geografia, alguns outros pertencentes a diversas instituições (para trabalhos de geologia, pedologia, zoologia, etc) além de alunos do curso de Geografia da Faculdade Nacional de Filosofia da Universidade do Brasil.

Foram estabelecidas quatro equipes de trabalho, de início com cerca de oito técnicos cada uma, abrangendo estudos de: A) geomorfologia (topografia e geologia), B) biogeografia (clima, medidas hidrográficas e vegetação e C) geografia humana (gêneros de vida, povoamento. Eram todos coordenados por um chefe, auxiliados por uma secretária.

Cada equipe dispunha de dois caminhões e do indispensável pessoal: motoristas, cozinheiros, ajudantes, etc. Em média, oito a dez pessoas.

Num caminhão instalava-se a alidade e no outro a régua eclímetro. Fazendo-se caminhamentos com visadas recíprocas, sobre pranchetas, havia a compensação de possíveis distorções. Pontos especiais, fora dessa linha mestra, eram a ela ligados por caminhamentos auxiliares, realizados com a alidade autorredutora.

O ponto de partida de cada itinerário era sempre um local onde houvesse coordenadas geográficas já determinadas.

Com o fim das férias da Faculdade de Filosofia, obrigando os alunos a retornarem ao Rio de Janeiro no fim de julho, tornou-se necessário um remanejamento dos técnicos nas diferentes equipes.

Os trabalhos, porém, prosseguiram, obedecendo à mesma sistemática já referida, a fim de atender às áreas que ainda restavam por estudar. 
O alojamento era feito em barracas (grandes, fornecidas pelo Exército) sendo o acampamento deslocado diariamente.

O Prof. Ruellan circulava entre as equipes, levando a orientação necessária ao desenvolvimento dos trabalhos, recolhendo o material já elaborado, além de atender à complementação de víveres. Essa $5^{\mathrm{a}}$ Equipe, que era denominada "Grupo de Direção" era formada pelo professor, duas secretárias, um desenhista e um encarregado de serviços gerais. Dispunha de seus próprios caminhões.

Foram, assim, levantados $1750 \mathrm{~km}$, em 65 dias. No total foram percorridos mais de $3.000 \mathrm{~km}$, já que alguns itinerários foram demarcados com bússolas, barômetros e velocímetro, havendo ainda as irradiações, várias vezes feitas.

As condições de trabalho fora, quase sempre, bastante duras, já que executadas em caminhão, a cavalo ou a pé, em pistas precárias (em sua maior parte) através dos Cerrados.

Mais tarde, no gabinete, foi possível contar com o apoio de fotografias aéreas (para algumas áreas) complementando observações feitas no campo.

A $2^{\mathrm{a}}$ expedição, sob a chefia do Eng. Fábio de M. S. Guimarães e contando com a orientação científica do Prof. Leo Waibel, estudou o planalto em seu conjunto, visando à compreensão das características gerais dessa região, tendo em vista, sobretudo, o problema da posição da nova capital do país.

Para atender a esses objetivos era preciso abranger a maior área possível, por meio de itinerários cuidadosamente planejados. Além das oito áreas escolhidas, foi necessário também realizar observações nos espaços existentes entre elas.

Ao contrário do $1^{\circ}$ grupo, o número de componentes do $2^{\circ}$ era bem mais reduzido nove técnicos, que, em boa parte do tempo atuação todos juntos. Esse grupo foi composto pelos cinco chefes de Secção da Divisão de Geografia do CNG, sob a direção do Eng. Fábio M. S. Guimarães e do Prof. Leo Waibel. Participaram ainda, mais um geógrafo do CBG e dois técnicos de Minas Gerais: um agrônomo e um botânico-prático, estes temporariamente.

Quando existiam estradas diferentes ligando dois pontos de interesse, o grupo se dividia em dois, reencontrando-se seus componentes em pontos previamente fixados. Nas áreas que exigiam observações mais detalhadas, várias irradiações foram feitas, partindo dos pontos que, pelo seu interesse, foram tomados como bases.

Os deslocamentos eram feitos em caminhões, cedidos pelo Governo de Minas Gerais e Goiás. Alguns percursos foram realizados de automóvel, a cavalo ou a pé, conforme as 
circunstâncias. Em determinadas áreas foram feitos sobrevoos com pequenos aviões (os “teco-tecos”): em número de quatro, totalizando cerca de $630 \mathrm{~km}$.

Dentro das atribuições que haviam sido conferidas a esse grupo não constavam levantamentos detalhados, tarefa consignada ao $1^{\circ}$ grupo. Não foram feitas, portanto, mensurações sistemáticas. Apesar disso, porém, dada a escassez de indicações altimétricas nos mapas da época, e pela importância que as condições de relevo apresentavam para os estudos em questão, foram realizadas muitas medidas com aneroides. Algumas anotações sistemáticas sobre os estados de tempo também foram feitas, realizando-se observações meteorológicas três vezes ao dia. Amostras de rochas e de solos, além de medidas em poços para determinar a profundidade do lençol freático foram também coletados.

À semelhança do $1^{\circ}$ grupo, os trabalhos destes desenvolveram-se de julho a setembro, tendo sido percorridos cerca de $6.000 \mathrm{~km}$. Se computadas as repetições de percurso, esse total ultrapassaria os $10.000 \mathrm{~km}$.

O número de dias de pesquisa de campo foi de 80.

Nas cidades que serviam de base temporária, o grupo reunido, realizava debate sobre as observações feitas, antecipando as discussões que, no regresso ao Rio de Janeiro, ocorreriam no gabinete, juntamente com a concatenação de todo o material coletado.

Os trabalhos de campo foram, assim, efetuados, praticamente, no mesmo período pelos dois grupos. Tendo eles, porém, atuado separadamente, isso teve a vantagem de possibilitar a comparação dos resultados obtidos por ocasião da coordenação final.

Terminados os trabalhos de campo os respectivos relatórios, foram os mesmos entregues ao Presidente da Comissão Especializada de Estudos Geográficos que, baseando-se nos dados fornecidos pelos mesmos, realizou o seu entrosamento, de modo a que o relatório final representasse uma síntese dos trabalhos realizados pelas duas expedições.

Este relatório indicou a Área C como sendo a preferencial para a localização do novo Distrito Federal. Essa Área C abrangia terras do Sul de Goiás e do Oeste do Triângulo Mineiro, achando-se indicada na relação das áreas propostas sob a designação "Uberlândia Tupaciguara".

Esse relatório foi entregue à Comissão Ampla (a que fora nomeada pelo Presidente da República). Teve essa, pois, em mãos duas indicações: uma, a antiga ( $9^{\circ}$ Retângulo Cruls) e outra, a da Área C, que acabava de lhe ser entregue. 
A decisão foi tomada por votação entre os 12 membros da Comissão: os que entendiam que o objetivo da mudança era, sobretudo, colonizador, com a ideia de ocupar grandes espaços do interior do país, votaram pelo Retângulo Cruls, tendo constituído a maioria (sete); os que visavam unicamente a solução da localização do novo Distrito Federal com a sede do Governo, optaram pela Área C, por entender que as condições oferecidas pela mesma, tanto por suas características físicas, quanto pelas estruturas básicas já existentes (facilidades de circulação, abastecimento, etc.), possibilitariam uma rápida transferência. A Área $\mathrm{C}$ recebeu cinco votos.

O resultado, portanto, foi de sete votos a cinco, a favor da Área do Retângulo Cruls.

Comunicada essa decisão ao Presidente da República, este enviou ao Congresso, a 21 de agosto de 1948, a mensagem portadora desse resultado, ressaltando, ao mesmo tempo, a importância do assunto.

Apesar disso, vários presidentes se sucederam e foi, somente, em 1956, com o Presidente Juscelino Kubitschek, que os trabalhos da construção de Brasília foram iniciados.

Brasília foi inaugurada em 21 de abril de 1960.

\section{Referências Bibliográficas}

CASTRO, Christovam Leite de. A transferência da capital do país para o Planalto Central. In: Revista Brasileira de Geografia. Ano VIII, nº 4, pp. 567-572. IBGE. Rio de Janeiro, 1946. . A mudança da Capital do País à luz da Ciência Geográfica. In: Revista Brasileira de Geografia. Ano IX, no 2, pp. 279-285. IBGE. Rio de Janeiro. 1947.

A mudança da Capital do País. In: Revista Brasileira de Geografia. Ano X, no 3, pp. 449-451. IBGE. Rio de Janeiro. 1948.

GUIMARÃES, Fábio de Macedo Soares. O Planalto Central e o problema da mudança da Capital do País. In: Revista Brasileira de Geografia. Ano XI, nº4, pp. 471-542. IBGE. Rio de Janeiro. 1949.

Trabalhos de campo e de gabinete da segunda expedição geográfica do Planalto Central. In: Revista Brasileira de Geografia. Ano XI, no 4, pp. 613-617. IBGE. Rio de Janeiro. 1949.

RUELLAN, Francis. Quelques problèmes de l'expédition charge de trouver des sites pour la nouvelle Capitale Fédérale des Estats Unis du Brésil. Bulletin de l'Association des Géographes Français. № 194-195 (mai-juin), 12 pg. Paris, 1948.

Recebido em 08 de maio de 2018.

Aceito em 14 de maio de 2018. 